\title{
ANALISIS KONSEP PEMIKIRAN KI HAJAR DEWANTARA DALAM PERSPEKTIF PENDIDIKAN KARAKTER
}

\author{
Sukri, Trisakti Handayani, Agus Tinus \\ FKIP Universitas Muhammadiyah Malang, Indonesia \\ Email:Y_shofy@yahoo.com
}

\begin{abstract}
Education is a tool to educated nation children who can bring them to enlightenment in totally, education has a purpose to put a nation buildings up that adhere with values of intelligence, sensitivity, and care to nation and country. This research expected can reconstruct national education on crisis set off the problem morality Indonesian nation, rebuild education thought. Ki Hajar Dewantara has purpose of giving answer on morality crisis, that cannot be able to stem the problem of the morality series contemporary Indonesian nation, so education comes back to the prominent in human building that has good individuality (character humans), like the education that has been aspiration by national education sire (Ki Hajar Dewantara). This research has the purpose of knowing some problems in the research focus of research object such as: (1) analyze or inspect the concept thought of education by Ki HajarDewantara. (2) Relevance the idea thought of education by Ki Hajar Dewantara with education character and this research using qualitative research method, whereas the method used in this research is Library Research. The aggregation of data did with investigation way to Ki Hajar Dewantara opuses, especially education and the concept of education idea. Whereas data analysis that used in this research is discourse analysis will reveal various literature from research object. The results of this research show that 1). The concept of education thought by Ki Hajar Dewantara is about humanist education based on independence, external and internal freedom that if you take the red yarn is education that human being or education that can form good students characters. First characteristic is a brilliant mind. Second, intelligent and skill. Third, health of body and spirit. Fourth, pious to the god. 2) The relevance of education concept thought by Ki Hajar Dewantara with education character that both want the same education able to make a form of the whole human, it is freedom human and good personality. This output research expected can give solution or contribution of thought in reconstruct national education for education purpose in building Indonesian character people like education that has been a concept by Ki Hajar Dewantara.
\end{abstract}

Keywords: Analysis; Education Character; Ki Hajar Dewantara

\section{PENDAHULUAN}

Pendidikan adalah media untuk mencerdaskan kehidupan bangsa dan membawa bangsa ini pada era aufklarung (pencerahan). Pendidikan merupakan tonggat untuk mengetaskan kemiskinan pengetahuan, menyelesaikan persoalan kebodohan, dan menuntaskan permasalahan bangsa yang seleman ini terjadi ( Yamin, 2009 : 15 ). Pendidikan juga bertujuan untuk membangun sebuah bangunan bangsa yang melekat dengan nilai-nilai kecerdasan, kepekaan, dan kepedulian terhadap bangsa dan Negara. Pendidikan dihadirkan untuk menyantarkan bangsa ini untuk mejadi bangsa yang beradab dan berbudaya. Pendidikan dilahirkan untuk memperbaiki segala kebobrokan yang sudah menggumpal di segala sendi kehidupan ini.

Pendidikan harus mampu mewujudkan manusia yang seutuhnya, karena pendidikan berfungsi sebagai proses penyadaran terhadap manusia untuk mampu mengenal, mengerti dan memahami relitas kehidupan seharihari. Kunci pendidikan, adalah kemanusiaan. Pendidikan harus dimulai dari persamaan persepsi pemangku pendidikan tentang mendidik itu sendiri.

Menurut Ki Hajar Dewantara dalam (Siswono, dkk, 2011: 176). Mengartikan pendidikan sebagai usaha menuntun 
segenap kekuatan kodrat yang ada pada anak baik sebagai induvidu maupun sebagai anggota masyarakat agar dapat mencapai kesempurnaan hidup.

Sesungguhnya pendidikan merupakan usaha bangsa ini membawa manusia Indonesia keluar dari kebodohan, dengan membuka tabir aktual-transenden dari sifat alami manusia (humanis). Di dalam pembukaan UUD 1945 dinyatakan bahwa tujuan kita membentuk negara kesatuan Republik Indonesia ialah untuk mencerdaskan kehidupan bangsa. Bangsa yang cerdas adalah bangsa yang dapat Survive didalam menghadapi segala permasalahan. Sedangkan Menurut pasal 3 UU No. 20 Tahun 2003 tujuan pendidikan nasional yaitu untuk berkembangnya potensi peserta didik agar menjadi manusia yang beriman dan bertakwa kepada Tuhan Yang Meha Esa, berakhlak mulia, sehat, berilmu, cakap, kreatif, mendiri, dan menjadi warga negara yang demokratis serta bertanggung jawab.

Merujuk pada pengertian dan tujuan dari pada pendidikan di atas. Maka sesunguhnya melihat potret pendidikan Indonesia sangat-sangatlah buruk sekali atau tidak relavan dengan amat UUD 1945 , dengan realitas pendidikan yang terjadi di saat ini. Sebut saja, bila ada banyak anak miskin, terlantar, dan tidak mampu bersekolah karena pertimbangan finesnsial. Wacana ini, telah menjadi penjajah kesadaran kritis. Tidak hanya itu, yang lebih parah lagi telah menjadi pemutus harapan bagi kelas termarginalkan. Praktik pendidikan pasar juga dilakukan dengan cara menggratiskan biaya sekolah, namun tetap saja mengambil pungutan dan menambah tarif biaya buku atau Lembar Kerja Siswa (LKS). Atas dasar fenomena tersebut, malah pemerintah melakukan pembiaran atas segala praktik pendidikan yang berorientasi pasar praktek pendidikan juga mahal, kasus pembodohan juga kerap sekali terjadi di dunia pendidikan saat ini. Anak-anak yang dibiarkan di dalam lingkungan yang sangat memprihatinkan ini, tentu memerlukan pendidikan yang penuh dengan harapan. Bukan hanya pendidikan yang memposisikan peserta didik sebagai objek dari perubahan, melainkan pendidikan yang memerankan mereka sebagai manusia yang memiliki hak (the pedagogy of hope).

Potret hitam dunia pendidikan indonesia tidak cukup di lihat dari manajemen pendidikan, kesetaraan pendidikan, dan juga kualitas pendidikan yang buruk. Akan tetap, di sisi lain juga menyamati problematika perjalan pendidikan yang tidak mampu mebentuk manusia indonesia yang berkarakter. Hal ini, bila menyamati perjalanan pendidikan kontemporer, bahwa pendidikan nasional tidak mampu membentuk manusia indonesia yang baik ( berkarakter).

MenurutNurulHudadalam(Naim, 2010 : 27 ) menemuka ragam persolan pendidikan yang melengkapi apa yang telah terjadi. Beberapa persoalan yang berhasil dipetakan ialah sistem pendidikan, peningkatan SDM seperti yang termaktub dalam tujuan pendidikan yakni menghasilkan manusia yang beriman dan bertakwa, berbudi pekerti luhur, berkepribadian, mandiri, cerdas, tangguh, kreatif, terampil dan beretos kerja yang tinggi, dinilai sebagai hal yang terlalu ideal dan sulit untuk diwujudkan dalam sistem pendidikan seperti sekarang ini. Hal ini disebabkan karena sistem pendidikan kita terbentur dalam kepincangan dan kesenjangan.

Permasalah-permasalah yang terjadi di dunia pendidikan dewasa ini, cukup kopleks sekali. Dimana dimulai dari permasalahan kurikulum pendidikan, UU Pendidikan, tenaga pendidikan yang kurang profesional dalam mendidik siswa, infaktruktur pendidikan yang masih belum maksiamal, dan paling marak di dunia pendidikan dewasa ini ialah permasalah degradasi moral pendidik maupun peserta 
didik dan juga para pemandu negara (pemerintah). Hal ini, jika melihat dari berbagai media, eleoktronik, cetak maupun lainnya. Bahwa yang menghiasi lembaran-lembaran maupun siaran dalam media tersebut ialah berita-berita terkait permasalahan degradasi moral pelaku pemerintahan, pelajar bahkan seorang pendidik. Oleh karena itu, salah satu peroblem dalam kehidupan pendidikan saat ini sebagai di tegaskan oleh Agus Suwignyo ( 2007 : 10), adalah lemahnya disposisi sikap. Disposisi sikap merupakan keselarasan antara tindakan dengan pengetahuan yang medasari tindakan.

Ironisnya, pemerintah yang harus memberikan tauladan, maka pejabat-pejabat itu sendiri yang sanggat gencar melakukan tindakan inmoral (Tindak pidana korupsi, Penyalahgunaan kekuasaan), begitupun dengan pendidik, pendidik yang harusnya, menjadi motivator, mediator, memberikan tauladan, sebagai orang tua bagi anakanak, malah menjadi seorang majikan yang biadap, dengan melakukan tindak kekerasan bagi siswanya, melakukan pelecehan terhadap siswi. Inilah merupakan sebuah ironis bagi seorang pendidik yang harusnya menyembangkan pendidikan membangun manusia yang baik, justruh, melanggar etika-etika atau sifat keprofesionalnya seorang pendidik sebagai pelaku pembentuk karakter siswa. Hal lain juga yang marak dan sulit dibendung dalam dunia pendidikan nasional dewasa ini ialah maraknya terjadi degradasi moral yang dilakukan oleh peserta didik itu sendi, dimana peserta didik melakukan tindakantindakan yang kurang baik. Tindakan tersebut yaitu tawuran, penggalahgunaan Narkoba, minuman keras, dan Free sex (seks bebas). Dan inilah potret paling sulit dibendung dalam dunia pendidikan Indonesia dewasa ini, pendidikan yang idealnya sebagai media atau alat untuk membentuk manusia yang baik, pendidikan yang harusnya melepaskan belenggu kebodohan bagi manusia, pendidikan yang harusnya mampu membentuk dan melahirkan regenerasi yang baik untuk melanjutkan bangsa dan Negara ini, seakan tidak mempunyai makna yang baik dalam perjalannya, karena jelas-jelas kita bisa melihat realitas yang terjadi dalam bangsa Indonesia. Dalam dunia pendidikan, secara sadar maupun tidak kita seringkali dibodohi dengan praktik pendidikan yang sangat kurang bermutu. Terlebih bahwa pendidikan saat ini memiliki trend "mutu" yang lebih mementingkan taraf internasional. Dengan kata lain, kualitas yang baik, sebenarnya ditentukan oleh internasionalisasi lembaga formil pendidikan.

Problematika yang terjadi dalam dunia pendidikan ini tidak terlepas dari kebijakan-kebijakan pemerintah sebagai pemandu pendidikan yang tidak melihat bagiamana terobosan-terobosan yang seharusnya dilakukan, demi menciptakan sebuah pendidikan yang mampu membangun manusia indonesia yang baik, sehingga nantinya akan melahirkan pendidikan yang baik, demi menyantarkan manusia indonesia yang berkarakter. Hal ini, bila dicermati dengan cerdik, permasalahn yang timbul dalam dunia pendidikan kita, ialah pendidikan yang hanya menekan pada pembentukan tingkat intelektual seorang peserta didik semata. Bukan pendidikan yang mampu membentuk karakter baik manusia Indonesia. Sebenarnya pendidikan yang harus berasakan budaya dan kearifan lokal orang indonesia. Dan hal pendidikan itu, sebenarnya telah dikonsepkan oleh Bapak pendidikan indonseia yaitu Ki Hajar Dewantara.

Konsep pendidikan $\mathrm{Ki}$ Hajar Dewantara dinilai mengalami kebekuan saat ini. Justru yang terjadi di Indonesia adalah pengagungan pada konsep pendidikan negara barat yang cenderung eksploitatif dan berorientasi pasar. Dunia pendidikan di Indonesia pada akhirakhir ini mulai mengalami kegamangan. 
Pasalnya, pendidikan nasional masih mencari-cari model pendidikan kebangsaan yang membangun karakter bangsa. Padahal karakter ini sudah kita miliki.

Gagasan pemikiran pendidikan $\mathrm{Ki}$ Hajar harus dimunculkan kembali, karena yang diharapkan mampu memberi jawaban yang selama ini, cukup meresahkan martabat kemanusiaan. Berbagai problem di atas adalah kegagalan pemerintah dalam menyelenggarakan pendidikan yang berkualitas. Sejarahwan dari Universitas Gadjah Mada, Sutaryo pun tak menampik bila pendidikan di Indonesia lebih berorientasi pada barat. Ia mengatakan bahwa konsep pendidikan $\mathrm{Ki}$ Hadjar Dewantara perlu dimunculkan untuk mencapai pendidikan ideal sesuai karakter bangsa.

Ki Hajar Dewantara merupakan pemikir dan juga tokoh pendidikan di indonesia yang selalu menyuarakan konsep pendidikan kritis terhadap pendidikan. Ia adalah salah satu toko pendidikan nasional, sekaligus bapak pendidikan indonesia dan pejuang kemerdekaan, yang secara intens mengkritik praktik pendidikan dan memberikan kontribusi pemikiran pendidikan nasional yang selama ini ada di Indonesia. Ki Hajar, selalu mencoba menawarkan solusi ilmiah dan rasional guna perbaikan pendidikan yang mengarah pada pendidikan yang memanusiakan manusia.

Ki Hajar Dewantara bukanlah satusatunya tokoh pendidikan kritis nasional yang ada. Namun, banyak pula para pedagogi kritis, di antaranya adalah Tan Malaka, KH. Ahmad Dahlan, KH. Hasyim Asyari, Mansour Fakir, Yb. Mangunwijaya, Toto Raharjo, Roem Topatimasam, Soedjatmoko, H.A.R. Tilaar dan juga tokoh pendidikan Kritis terkemuka dari Brazil, yaitu Paulo Freire. Menganalisis pemikiran Ki Hajar Dewantara dalam kajian ini, bukan semata-mata untuk memposisikan bahwa Ki Hajar Dewantara sebagai tokoh sentral pendidikan. Namun, nilai tambah yang membuat kajian ini menjadi sangat menarik adalah, kiprah Ki Hajar di dunia aktivisme pendidikan nasional yang selalu mencoba melakukan perubahan (social change) di tengah masyarakat secara langsung. Ki Hajar merupakan seorang jurnalis, pemikir, aktivis politik, tokoh pendidikan dan kebudayaan. Sehingga akhirnya dengan kiprahnya itu, Ki Hajar Dewantara jadikanlah sebagai bapak pendidikan dan juga pahlawan pendidikan nasional. Dengan kata lain, ia merupakan tokoh kunci, yang begitu berani melakukan transformasi sosial dan merespon segala permasalahan kontemporer yang ada saat ini. Salah satu konsep pendidikan Ki Hajar Dewantara diaplikasikan lewat rumusan Pancasila. Mengamalkan Pancasila dengan baik dan benar bisa membentuk manusia berbudaya yang cocok dengan bangsa Indonesia.

Pemikiran Ki Hajar Dewantara kembali dipertimbangkan untuk diaplikasikan dalam dunia pendidikan saat ini. Slogan Tut Wuri Handayani sudah selayaknya dimaknai secara mendalam oleh para stake holder pendidikan terutama guru sebagai ujung tombaknya, sehingga tercipta pendidikan yang mampu memerdekakan manusia seperti apa yang dicita-citakan Ki Hajar Dewantara.

Konsep pemikiran pendidikan oleh Ki Hajar Dewantara dijelaskan dalam 2 teori yaitu Pendidikan dan Kebudayaan dan Taman Siswa. Dari kedua konsep itu diharapkan bisa memberikan pencerahan bagi para pendidik secara khusus serta semua kalangan masyarakat secara umum untuk melakukan perubahan terhadap pendidikan. Pendidikan karakter merupakan upaya terencana untuk menjadikan peserta didik mengenal, peduli dan menginternalisasi nilainilai sehingga peserta didik menjadi insani kamil. Dimana tujuan pendidikan karakter meningkatkan mutu penyelenggaraan dan hasil pendidikan di sekolah melalui pembentukan karakter peserta didik secara 
utuh, terpadu dan seimbang, sesuai dengan standar kompotensi lulusan.

Adapun nilai-nilai yang perlu dihayati dan diamalkan oleh guru saat mengajarkan mata pelajaran di sekolah adalah: religius, jujur, toleran, disiplin, kerja keras, cerdas, kreatif, mandiri, demokratis, rasa inggin tahu, rasa kebangsaan, cintah tanah air, menghargai prestasi, bersahabat/ komunikatif, cinta damai, senang membaca, peduli social, peduli lingkungan, dan tanggung jawab. Dalam hal ini, Ki Hajar Dewantara memberikan sumbangsi pemikiran tentang pendiddikan nasional, dimana pendidkan yang menekan pada kebudayaan sendiri yaitu kebudayaan Indonesia.

Gagasan yang menarik dikaji dari Ki Hajar adalah konsep pancadarma Perguruan Tamansiswa yang disusun pada 1947. Konsep ini, Ki Hajar seolah ingin mengungkapkan bahwa usaha-usaha mencerdaskan kehidupan bangsa harus memiliki landasan yang kuat. Asas-asas pancadarma ini merupakan intisari dari karakter pendidikan Indonesia. Jadi, dilihat dari pengertian pendidikan karakter dan pemikirian Ki Hajar tentang pendidikan. Maka konsepsi pemikiriran $\mathrm{Ki}$ Hajar Dewantara terhadap pendidikan karakter yaitu mempunyai relefansi membentuk manusia indonesia seutuhnya sesuai dengan kebudayaan nasional.

Pendidikan karakter yang dimaksud dalam skripsi ini adalah pendidikan yang mengantarkan peserta didik memmpunyai pribadi yang luhur, tanggung jawab mempunyai nasionalisme dan mempunyai jiwa kritis yang sejatinya dimiliki oleh siswa. Oleh karena itu perlu mengkaji kembali konsep pemikiran $\mathrm{Ki}$ Hajar Dewantara dalam pendidikan. Khususnya yang di kaji dalam penelitian ini ialah konsep Pemikiran Ki Hajar Dewantara setelah pulang diasingkan dari Negara belandan dengan membangun Sekolah Taman Siswa, dengan harapan dapat memberikan sumbangan pemikiran terhadap dunia pendidikan, khususnya pendidikan Karakter.

\section{METODE}

Metode penelitian ini adalah kajian pustaka (library research). Kajian pustaka merupakan teknik penelitian dengan cara melakukan penelusuran-penelusuran tentang konsep-konsep pemikiran Ki Hajar Dewantara. Dalam mempermudah mendapatkan hasil dari pada kajian pustaka terhadap penelitian ini, yakni peneliti menggunakan teknik membaca dan menganalisis segala tulisan Ki Hajar Dewantara yang ada tentang pendidikan, politik, maupun kebudayaan.

Penelitian yang digunakan dalam kajian pustaka ini merupakan penelitian kualitatif, di mana data yang hendak diteliti, adalah data-data yang memiliki kualitas makna-makna tertentu. Atas penggalian terhadap makna-makna tersebut, diharapkan akan menemukan makna-makna terhadap realitas, peristiwa, aktivitas sosial, persepsi dan pemikiran yang diajukan sebagai obyek analisis atau diskursus utama penelitian (Sukmadinata, 2007: 60).

Pendekatan dalam penelitian ini menggunakan pendekatan kualitatif karena data yang dihasilkan berupa data deskriptif dalam bentuk pernyataan-pernyataan atau kata-kata tertulis yang berasal dari sumber data yang diamati atau diteliti agar lebih mudah dalam memahami (Natsir, 1998: 62). Sedangkan jenis penelitiannya penulis menggunakan jenis penelitian studi pustaka (library research) yaitu penelitian yang berdasarkan pada kajian tulisan-tulisan atau pustaka yang sesuai dan relevan dengan penelitian tersebut. Penelitian ini dilakukan lewat beragam informasi kepustakaan (buku, ensiklopedi, jurnal ilmiah, koran, majalah dan dokumen) (Zed, 2004 : 89 ). Studi pustaka digunakan dalam penelitian ini karena efektif dan efisien untuk menganalisis tentang konsep pemikiran $\mathrm{Ki}$ Hajar Dewantara. 
Menurut M. Nazir (1988: 111), dalam bukunya yang berjudul 'Metode Penelitian" mengemukakan bahwa yang dimaksud denga Studi kepustakaan adalah teknik pengumpulan data dengan mengadakan studi penelaahan terhadap buku-buku, literatur-literatur, catatan-catatan, dan laporan-laporan yang ada hubungannya dengan masalah yang dipecahkan.

Riset pustaka sekaligus memanfaatkan sumber perpustakaan untuk memperoleh data penelitiannya. Tegasnya riset pustaka membatasi kegiatannya hanya pada bahanbahan bacaan meliputi buku-buku, teks jurnal, majalah-majalah ilmiah dan hasil penelitian yang berhubungan dengan objek kajian tersebut koleksi perpustakaan saja tanpa memerlukan lapangan (Zed, 2004: 1-2).

Secara tegas pula Mestika Zed berargumen, bahwa riset pustaka tidak hannya sekedar urusan membaca dan mencatat literatur atau buku-buku sebagaimana yang sering dipahami banyak orang selama ini. apa yang disebut dengan riset pustaka atau teks ini ialah serangkaian kegiatan yang berkenaan dengan metode pengumpulan data pustaka, membaca dan mencatat serta mengolah bahan penelitian. Jadi tema pembahasan kita saat ini bukan bermaksud untuk mengajarkan bagaimana seorang menjadi ahli perpustakaan, melainkan untuk memperkenalkan penelitian kepustakaan (literatur) secara garis besar (Zed, 2008: 3 ).

\section{HASIL DAN PEMBAHASAN}

Pembahasan tentang konsep pemikiran pendidikan KI Hajar Dewantara dan relevansinya terhadap pendidikan karakter ialah telah di ringkas sebagaimana di bawah ini. Berdasarkan uraian di atas tentang pandangan dan konsep pendidikan menurut Ki Hajar Dewantara. Menurut penulis inilah kaitan ataupun relevansinya dengan pendidikan karakter yang seharusnya dibangun dapat dideskripsikan atau di ringkas sebagai berikut: pertama, 18 Nilainilai yang perlu diinternalisasikan kepada peserta didik dalam pengembangan karakter adalah: religius, jujur, toleran, disiplin, kerja keras, cerdas, kreatif, mandiri, demokratis, rasa ingin tahu, semangat kebangsaan, cinta tanah air, menghargai prestasi, bersahabat/ komunikatif, cinta damai, senang membaca, peduli sosial, peduli lingkungan, dan tanggung jawab. Kedua, Penyelenggaraan pendidikan jangan terjebak pada pencapaian target sempit, yang hanya melakukan transfer of knowledge (transfer pengetahuan) melainkan perlu dengan sengaja (by design) mengupayakan terjadinya transformasi nilai untuk pembentukan karakter anak bangsa. Ketiga, Pembentukan karakter peserta didik perlu melibatkan tri pusat pendidikan (keluarga, sekolah, dan masyarakat) secara sinergis dan integral. Keempat, Pengembangan karakter peserta didikperlu memperhatikan perkembangan budayabangsa sebagai sebuah kontinuitas menuju ke arah kesatuan kebudayaan dunia (konvergensi), dan tetap memiliki sifat kepribadian di dalam lingkungan kemanusiaan sedunia (konsentris). Kelima, Asas dan dasar pendidikan yang digagas $\mathrm{Ki}$ Hadjar Dewantara merupakan landasan dasar yang kokoh untuk membangun karakter bangsa, bersendi pada budaya bangsa dengan tidak mengabaikan budaya asing. Keenam, Sistem pendidikan yang dikemukakan Ki Hajar Dewantara (ing ngarsa sung tuladha, ing madya mangun karsa, dan tut wuru handayani) adalah wasiat luhur yang patut diterapkan dalam mengembangkan karakter peserta didik. Ketujuh, Corak dan cara pendidikan menurut pandangan Ki Hajar Dewantara patut kita jadikan sebagai acuan dalam pengembangan pendidikan karakter. Pendidikan karakter harus bercorak nasional dengan menerapkan cara-cara; pemberian contoh, pembiasaan, wulangwuruk, laku, dan pengalaman lahir-batin. 


\section{SIMPULAN}

Setelah mengkaji konsep pemikiran pendidikan Ki Hajar Dewantara dalam Taman siswa tentang pendidikan yang meliputi pendidikan humanistik yang membentuk karakter maka dapat disimpulkan dalam beberapa bagian berikut ini: Konsep pemikiran pendidikan Ki Hajar Dewantara dapat di telusuri pada saat tahun mendirikan Tamansiswa. Ki Hajar Dewantara $\mathrm{dkk}$, menyatakan berdirinya National Onderwij Institut Taman siswa atau Perguruan Taman siswa di Yogyakarta Pada 3 Juli 1912. Kemudian Ki Hajar Dewantara mengerakan perkembangan Taman siswa setelah sepulang dari negara Belanda pada tahun 1919. Lahirnya tamansiswa didorong oleh keadaan dimana bangsa yang masih mengalami kekurangan dan pengajaran dalam pendidikan. Menurut rakyat perlu disiapkan untuk memiliki jiwa yang sehat. Dari kesadaran itulah, maka lahirlah Taman siswa sebagai bentuk gerakan pendidikan untuk melawan sistem pendidikan kolonial yang saat itu tidak sesuai dengan semangat bangsa Indonesia. Pergerakan itu, dilakukan untuk mencapai cita-cita membangun manusia Indonesia yang berkarakter. Untuk mencapai citacita itu. Maka, Ki Hajar mengembangkan konsep pengajaran melalui Metode Among. Metode Among merupakan salah satu teknik pengajaran dalam pendidikan yang menunutun tujuan membentuk jiwa anakanak sebagai bangsa yang berkarakter, membimbing manusia agar bisa hidup dengan kecakapan dan kepandaian sendiri, menciptakan manusia yang berguna bagi diri sendiri dan masyarakat. Ki Hajar Dewantara juga menyajarkan pentinya sistem Tri Pusat pendidikan yang satu sama lain saling berkaitan yaitu pendidikan dalam keluarga, sekolah dan masyarakat. Ketiga hal ini sangat berpengaruh dalam membentuk watak dan kepribadian anak. Dalam mendidik anak harus diberi tuntunan dan dorongan agar tumbuh dan berkembang atas dasar kodratnya sendiri. Dan teknik mendidik dan mendorong yang lahir dari Tamansiswa atas pemikiran Ki Hajar Dewantara yaitu terdapat pada Trilogi, Ing Ngarsa Sung Tuladha, Ing Madya Mangun Karsa, Tut Wuri Handayani, yang artinya guru disebut sebagai fasilitator, mediator dan motivator yang akan mengantarkan peserta didik mengembangkan pendidikanya, hingga dapat membangun jiwan siswa berkarakter kuat.

Pendidikan di Indonesia ini telah mengalami kemorosotan nilai moral penghargaan terhadap peserta didik, pembentukan karakter, pendidikan memanusiakan manusia (Humanis), belenggu ketidakadilan pendidikan, pendidikan yang monoton, pendidikan yang menjauhkan peserta didik dari kebudayaan, pendidikan yang hanya menekan pada tingkat intelektulitas dan pendidikan yang tanpa memberikan ruang kebebasan untuk berpikir kritis bagi peserta didik. Oleh karena itu, pemikiran Ki Hajar Dewantara perlu di rekonstruksi. Hal itu, disebabkan pemikiran pendidikan $\mathrm{Ki}$ Hajar sangat mempunyai relevansi terhadap pendidikan Karakter. Karena, Pendidikan karakter juga dikatakan sebagai satu pranata sosial yang tidak hanya melihat bahwa pendidikan itu sebagai upaya mencerdaskan semata, melainkan sejalan dengan pemikiran pendidikan Ki Hajar Dewantara dalam Taman siswa yang sama-sama menginginkan pendidikan membangun manusia berkarakter, mempunyai tingkat intelektual yang baik, dan mempunyai moralitas yang tinggi dan akhirnya membawa peserta didik ke insani yang baik, sesuai dengan hakikat kemanusiaan.

Melihat problematika yang dihadapi dunia pendidikan saat ini, maka penulis berharap tulisan tentang pendidikan ini bisa memberikan sumbangsi yang berarti bagi pendidikan, khususnya pendidikan karakter. 
Pemikiran pendidikan Ki Hajar Dewantara harus di rekonstruksi demi menjawab problematika pendidikan dalam membentuk manusia Indonesia yang lebih baik, dan ini perlu diperhatikan dan di renungi bagi pemerintah maupun praktis pendidikan saat ini. Pendidikan dalam proses pembelajaran memang harus sesuai dengan corak kultur dimana pendidikan tersebut ada, namun tidak bisa dilepaskan dari peranan semua pihak pelaku perubahan pendidikan untuk menggagas kembali konsep pendidikan pemikiran Ki Hajar Dewantara dalam membangun karakter peserta didik yang memang belum secara maksimal di terapkan di dunia pendidikan. Para pengampu pendidikan harus melihat realita yang terjadi di dunia pendidikan saat ini, dan semoga tulisan ini bisa dijadikan rujukan guna memperdalam dan memperbaikan teori pada presentasi gagasan tentang pendidikan nasional.

\section{DAFTAR PUSTAKA}

Azzet Muhaimin Akhmad. 2011. Urgensi Pendidikan Karakter Di Indonesia. Jogjakarta: Ar-Ruzz Media.

Arikunto Suharsimi. 2003. Manajemen Penelitian. Jakarta: PT. Rineka Cipta.

Asmani Ma'mur Jamal. 2012. Buku Panduan Internalisasi Pendidikan Karakter di Sekolah. Jogjakarta: Diva Press.

Agus Suwigno. 2007. Dasar-dasar Intelektualitas, Yang Terlupakan dalam Hubungan Universitas dan Dunia Kerja. Yogyakarta : LkiS,

Bungin, Burhan. 2010. Penelitian Kualitatif. Jakarta: Prenanda Media Group.

Bahrudi dan Moch. Hakim. 2009. Pendidikan Humanistik konsep, teori, dan aplikasi praktris dalam dunia pendidikan. Jogyakarta : ArRuzzmedia

Dewantara, Ki Hajar. 1997. Majelis Luhur Persatuan Taman Siswa. Yogyakarta: Wasita.
Fudyartanta, Ki. 2010. Membangun Kepribadian dan Watak Bangsa Indonesia, Yang Harmonis dan Intgral. Yogyakarta: Pustaka pelajar.

Gunawan, Ki. 1989. Aktualisasi konsep pendidikan Ki Hadjar Dewantara dalam sistem pendidikan nasional Indonesia di Gerbang XXI, dalam Ki hadjar Dewantara dalam pandangan para cantrik dan mantriknya. Yogyakarta: MLPTS..

KBBI. 2002. Kamus Besar Bahasa Indonesia. Jakarta: Balai Pustaka.

Lickona, Thomas. 2013. Educating For Charakter, Mendidik Untuk Membentuk Karakter, Bagaiman Sekolah Dapat mengajarkan Sikap Hormat dan Tanggung Jawab. Jakarta : Bumi Aksara.

Muslich, Masnur. 2011. Pendidikan Karakter Menjawab Tantangan Krisis Multidimensional. Jakarta: Bumi Aksara.

Moleong, Lexi J. 2007. Metodologi Penelitian Kualitatif. Bandung: PT Remaja Rosda Karya.

Mu'arif, Syamsul. 2005. Pendidikan Pluralisme di Indonesia. Yogyakarta: Logung Pustaka.

Nazir, M. 2003. Metode Penelitian. Jakarta, Ghalia Indonesia

Natsir, M. 1998. Metode Penelitian. Jakarta: Balai Pustaka.

Pidarta M (1999) “Studi Tentang Landasan Kependidikan, Jurnal, Filasafat, Teori dan Praktek Kependidikan", Jakarta.

Puskur.(2009 )" Pengembangan dan Pendidikan Budaya \& Karakter Bangsa: Malang: Pedoman Sekolah.

Rahman Arif( 2008 )"Memahami Pendidikan dan Ilmu Pendidikan', Yogyakarta: Laksbak Mediatama.

Raharjo Suparto, ( 2009 ) “ Ki Hajar Dewantara Biografi Singkat" 19891959 Yogyakarta: Grasai House Of book. 
Reksohadiprodjo Ki Muchammad Said( 1989 ),"Masalah-masalah Pendidikan Nasional”. Jakarta: CV. Haji Masagung.

Rifa'il Muhammad, ( 2011 ), “ Sejarah Pendidikan Nasional Dari Masa Klasik Hingga Moderen “ Jogjakarta, Am Ar- Ruzz Media.

Supratman, ( 2004 ),"Mencerdaskan Kehidupan Bangsa", Yogyakarta: Laksbak Mediatama.

Satori Djam'an dan Komariah Aan (2009), “ Metode Penelitian Kualitatif”, Bandung : Alfabeta.

Soeratman Darsita, ( 1985 ) "Depertemen Pendidikan dan Kebudayaan" Jakarta: Insist Press.

Siswoyo Dwi Dkk, ( 2011 ), “ IlmuPendidikan", Yogyakarta:Uny Press .

Surjomihardjo Abdurrchaman, ( 1986 ), “ Ki Hajar Dewantara dan Tamansiswa Dalam Sejarah Indonesia Moderen", Yogyakarta: SinarHarapan.

Suyadi (2013) “ Strategi Pemberlajaran Pendidikan Karakter", Bandung: Rosda.

Sukmadinata Syaodih Nana ( 2007 )., “ Metode PenelitianPendidikan ", Bandung: RosdaKarya.

Sukardjo M dan Ukim Komarudin (2010) "Landasan Pendidikan Konsep dan Aplikasinya" Yogyakarta : Rajawali.

Sukardi, ( 2009), "Metodologi Penelitian Pendidikan", Jakarta : PT Bumi askara:
Prof. Dr. Sugiyono (2011), "Metode Penelitian Kuantitatif dan Kualitatif dan R dan D".Bandung : Alfabeta.

Tilaar H.a.r, ( 2002 ), " Pendidkan Kebudayaan dan Masyarakat Madani Indonesia", sebagai reformasi pendidikan Nasional, Bandung: Rosda.

Tauchid Muchammad dan Suratman Ki ( 1988). "Taman Siswa dan Sila Ketuhanan Yang Maha Esa". Yogyakarta: MLPTS.

UnjL km Kreati Tim ( 2011 ), “ Restorasi Pendidikan Indonesia, Menuju masyarakat terdidik berbasis budaya", Yogyakarta: Ar-Ruzz Media.

Undang-undang republik Indonesia Nomor 20 Tahun 2003 "Tentang Sistem Pendidikan Nasional", Bandung : focus media.

Yoce Darma Ali, ( 2009 ) “Analisis Wacana Kritis”, Bandung: Yrama Widya.

Yamin Moh, ( 2009 ) " Menggugat Pendidikan Indonesia " Belajar Dari Paulo Freire dan Ki Hajar Dewantara, Jogjakarta : Ar-Ruzz Media.

Zed Mestika (2008), “ Metode Penelitian Kepustakaan", Jakarta : Yayasan obor Indonesia.

Zubaidi, 2011. "Desain Pendidikan Karakter", Jakarta: Prenada Media Group. 